\title{
Immunohistochemical expression of CD44s in renal cell carcinoma lacks independent prognostic significance
}

\author{
Walter Henriques da Costa, Rafael Malagoli Rocha, Isabela Werneck da Cunha, Gustavo Cardoso Guima- \\ raes, Stenio de Cássio Zequi
}

\author{
A.C. Camargo Hospital, Sao Paulo, Brazil
}

\section{ABSTRACT}

Purpose: To analyze the immunohistochemical expression of the standard isoform of CD44 (CD44s) adhesion molecule in clear cell renal cell carcinoma (CCRCC) and its impact on clinical outcomes.

Materials and Methods: Ninety-nine consecutive patients treated surgically for RCC between 1992 and 2009 were selected. A single pathologist reviewed all cases to effect a uniform reclassification and determine the most representative tumor areas for construction of a tissue microarray. The same pathologist, who was blinded to the outcome of the cases, semi-quantitatively scored the staining intensity of CD44s in all specimens. The counting was done using the $\mathrm{H}$-Score algorithm.

Results: Of the 99 immunostained RCC specimens, 57(57.7\%) showed low expression, and 42(42.4\%) showed high expression levels of CD44s. The expression of CD44s was directly associated with tumor size $(p=0.03)$, clinical stage $(p=0.02)$ and Fuhrman grade $(p=0.02)$. Disease specific survival (DSS) rates for patients whose specimens expressed low and high levels of CD44s was $88.1 \%$ and $67.5 \%$, respectively $(p=0.009)$. Progression free survival (PFS) rates in patients with low and high expression of CD44s were $78.8 \%$ and $61.7 \%$, respectively $(\mathrm{p}=0.05)$. Classical features such as the presence of metastasis and clinical stage remained isolated predictors of survival.

Conclusions: Immunohistochemical expression of CD44s was associated with important clinical variables such as stage and Fuhrman grade. However, it was not an independent predictor of survival. Therefore, we believe it has a limited role as a prognostic marker in patients with CCRCC.

\section{ARTICLE INFO}

\section{Key words:}

Carcinoma, Renal Cell;

Antigens, CD44; Biological

Markers; Prognosis

Int Braz J Urol. 2012; 38: 456-65

Submitted for publication:

March 06, 2012

Accepted after revision: June 14, 2012

\section{INTRODUCTION}

It is known that renal cell carcinoma (RCC) is responsible for 3\% of all malignancies. In America, it is estimated that approximately 58,000 new cases were diagnosed and 13,000 patients died from RCC in 2010 (1). It is the seventh most common malignancy in men and the ninth most common in women, and occurs predominantly in the sixth and seventh decades of life (1).
Despite recent advances in the diagnosis and treatment of RCC, it is still a tumor of unpredictable presentation and clinical outcome. Currently, the only potentially curative treatment is surgery, through either radical nephrectomy or nephron sparing procedures. Systemic therapies such as anti-angiogenic agents show mixed results and often disappointing outcomes (2). Such drugs are available for patients with metastatic disease and its possible use as adjuvant or neoadjuvant agents 
is still not well defined (3). Therefore, individual markers of tumor aggressiveness are needed (4-6).

CD44 and its variants constitute a protein family that is expressed in the cytoplasmic membrane and mediates cell-cell and cell-extracellular matrix interactions. It is encoded by a single gene and is subjected to post-translational modifications through alternative splicing. Its chief ligand is hyaluronic acid, an important component of the extracellular matrix (ECM) (7). As a molecule involved in mechanisms of cell motility, CD44 has been used as a marker of tumor aggressiveness in a number of malignancies such as stomach, liver and breast. However, in RCC there are contradictory results, with some series supporting the role of CD44 as a prognostic marker (8-10) while in other studies its importance as a predictor of survival was not confirmed $(11,12)$.

The purpose of this study was to analyze the immunohistochemical expression of the standard isoform of CD44 (CD44s) in clear cell RCC (CCRCC) and examine its association with pathological features and its impact on clinical outcomes.

\section{MATERIALS AND METHODS}

\section{Patients}

Ninety-nine consecutive patients submitted to radical nephrectomy or partial nephrectomy for RCC between 1992 and 2009 were selected from the medical records of our institution. The clinical data were obtained from medical charts in the hospital archives. A single pathologist (IWC) reviewed all cases to effect a uniform reclassification and determined the most representative tumor areas for construction of a tissue microarray. Our internal review board approved this study.

The following variables were included in the data bank: age, gender, ECOG status, smoking status, time since diagnosis, type of surgery, staging (TNM AJCC/UICC 2002), Furhman grade, histological subtype (World Health Organization (WHO) 2004), microvascular invasion (MVI), lymph node involvement, presence of tumor necrosis, follow-up period, presence of metastases, clinical situation at the end of the study, storage time of the paraffin embedded samples and immunohistochemical expression of CD44s.

\section{Construction of tissue microarray}

Two cylinders, measuring $2 \mathrm{~mm}$ in diameter, taken from different parts of the tumor were used to build a tissue microarray (TMA). Two cylinders from previously evaluated tumors--one that was positive for CD44s and one that was CD44s-negative--were included as internal controls. Sequential $4 \mu \mathrm{m}$ sections were generated and stained with hematoxylin and eosin (the first and last sections) to confirm the diagnosis, and the intervening sections were examined by immunohistochemistry.

\section{Immunohistochemistry}

The sections were mounted on positively charged glass slides, dried for $30 \mathrm{~min}$. at $37^{\circ} \mathrm{C}$, deparaffinized in xylene, and rehydrated in a series of graded alcohols. The sections were then incubated with a primary antibody against CD44 standard isoform (Novocastra ${ }^{\circledR}$ clone F10-44-2, Newcastle, UK) at 1:40 for 30 minutes. All immunohistochemistry procedures were performed automatically in a Link 48 autostainer $\left(\right.$ DAKO $^{\circledR}$ ) using the Flex Plus visualization system according to the supplier's specifications. For control staining of CD44s, 17 specimens of non-neoplastic renal parenchyma that were at least $1.0 \mathrm{~cm}$ from the tumor lesion were included. Both renal cortex and renal medulla were evaluated.

The same pathologist, who was blinded to the outcome of the cases, semi-quantitatively scored the staining intensity of CD44s in all specimens. The counting was done using the $\mathrm{H}$-Score algorithm (13). For H-score assessment, fields were at X400 magnification and the staining intensity in the malignant cell was scored as $0,1,2$, or 3 corresponding to the presence of negative, weak, intermediate, and strong brown staining, respectively. The total number of cells in each field and the number of cells stained at each intensity were counted. The average percentage positive was calculated and the following formula was applied: $\mathrm{H}-$ Score $=(\%$ of cells stained at intensity category 1 $\mathrm{x} 1)+(\%$ of cells stained at intensity category $2 \mathrm{x}$ $2)+(\%$ of cells stained at intensity category $3 \times 3)$. A H-Score between 0 and 300 was obtained where 300 was equal to $100 \%$ of tumor cells stained strongly $(3+)$. For better interpretation, categories 
"low-" and "high-" expression levels were used based on the median value of $\mathrm{H}$-Score algorithm.

\section{Statistical Analysis}

Analyses were performed using SPSS for Windows, version 17.0 (SPSS ${ }^{\circledR}$, Chicago, Ill). To verify the association between CD44s expression and other variables, Pearson chi-square test was performed. Fisher's exact test was applied to cases in which the expected frequency was less than 5 . The level of significance was 5\%. Comparisons between the degrees of expression of CD44s in non-neoplastic renal parenchyma and CCRCC tissue were made by Kruskal-Wallis test and Mann-Whitney test.

Disease-specific survival (DSS) was defined as the interval between the primary surgery and the last follow-up visit or disease-related death. Progression-free survival (PFS) was defined as the interval between the primary surgery and the last follow-up visit if the patient showed no evidence of disease, recurrence, or metastasis of RCC. DSS and PFS were examined using Kaplan-Meier curves. To compare the estimated curves for each category within a given variable, log-rank test was used. The level of significance was 5\%. Cox proportional hazards model was used to determine which variables influenced survival. Variables that significantly impacted survival in univariate analysis were included in multivariate analyzes. The confidence interval was 5\%.

\section{RESULTS}

\section{Characterization of patients}

Of the total 99 patients, $71(71.7 \%)$ patients underwent radical nephrectomy; 28 (28.3\%) were treated with nephron-sparing procedures, all of which had negative margins. The patients ranged from age 27 to 79 years (average 55.5 years). The mean postoperative follow-up period was 43 months and ranged from 0 to 178 months. There was metastatic disease at the initial clinical presentation in 13 (13.3\%) patients; 50/99 (51.5\%) presented with $\mathrm{T} 1$ stage disease. The cohort mean tumor size was $7.4 \mathrm{~cm}$. Over 5 years, $21(21.2 \%)$ patients died of CCRCC. The clinical and pathological features of the patients are listed in Table-1.
Of the 99-immunostained RCC specimens, 57 (57.6\%) showed low expression, and 42 (42.4\%) showed high expression of CD44s, which was evenly distributed through the plasma membrane, cytoplasm and cell nucleus (Figure-1). In fact, it was observed an even distribution of the staining instead of the presence of high spots. Additionally, when divided into two groups according to storage time of the paraffin embedded samples (up to 10 years and above 10 years), we noted no significant impact on staining intensity $(p=0.42)$.

CCRCC cases expressed higher levels of CD44s compared with normal tissue $(p=0.01)$. The mean expression score for $\mathrm{CD} 44 \mathrm{~s}$ in non-neoplastic tissues was $88(\mathrm{sd}=11.1$, median $=81)$. In CCRCC samples, the mean score was $143(\mathrm{sd}=12.9$, median $=149$ ) (Figure-2).

The expression of CD44s was directly associated with incidental tumors $(p=0.01)$, tumor size $(p=0.03)$, lymph node involvement $(p=0.003)$, microvascular invasion (MVI) $(p=0.01)$, clinical stage $(p=0.002)$ and Fuhrman grade $(p=0.02)$ as shown in Table- 1 .

\section{Survival analysis}

Disease-related death occurred in 21 patients (21.2\%) during follow-up. The following variables were associated with 5-year disease-specific survival (DSS) rates in the univariate analysis: clinical stage ( $p<0.001$ ), MVI $(p<0.001)$, tumor size $(\mathrm{p}<0.001)$, necrosis $(\mathrm{p}<0.001)$, metastasis at presentation ( $\mathrm{p}<0.001)$, Fuhrman grade $(\mathrm{p}<$ $0.001)$, and ECOG PS ( $p=0.009)$. The 5 -year progression-free survival (PFS) rate was 70.7\%. Metastasis at diagnosis ( $<<0.001)$, MVI $(\mathrm{p}=0.007)$, clinical stage $(p=0.001)$, tumor size $(p<0.001)$, Fuhrman grade $(\mathrm{p}<0.001)$, and ECOG PS $(\mathrm{p}=0.01)$ were linked to 5-year PFS rates in the univariate analysis (Table-2).

DSS rates based on CD44s expression are shown in Figure-3A. The 5-year DSS for patients whose specimens expressed low and high levels of CD44s was $88.1 \%$ and $67.5 \%$, respectively ( $\mathrm{p}=$ 0.009 ). Five-year PFS rates in patients with low and high expression of CD44s were 78.8\% and 61.7\%, respectively ( $\mathrm{p}=0.05)$ (Figure-3B).

In the multivariate analysis, clinical stage $(p<0.001)$, metastasis at diagnosis $(p<0.001)$, and 
Table 1 - Patients, pathological characteristics, and association between variables and CD44s expression.

\begin{tabular}{|c|c|c|c|c|}
\hline Variable & $\begin{array}{l}\text { CD44s } \\
\text { H-Score }\end{array}$ & Low expression $n(\%)$ & High expression n (\%) & $p$ value \\
\hline \multicolumn{5}{|l|}{ Gender } \\
\hline Male & 141,14 & $35(57)$ & $26(43)$ & \\
\hline Female & 151,63 & $22(58)$ & $16(42)$ & 0.56 \\
\hline \multicolumn{5}{|l|}{ Smoking } \\
\hline No & 148,77 & $37(60)$ & $25(40)$ & \\
\hline Yes & 139,13 & $22(60)$ & $15(40)$ & 0.57 \\
\hline \multicolumn{5}{|c|}{ Incidental tumor } \\
\hline No & 172,87 & $25(42)$ & $34(58)$ & \\
\hline Yes & 131,28 & $27(68)$ & $13(32)$ & 0.01 \\
\hline \multicolumn{5}{|c|}{ Clinical Stage } \\
\hline I or II & 130,98 & $43(72)$ & $17(28)$ & \\
\hline III or IV & 167,00 & $16(41)$ & $23(59)$ & 0.02 \\
\hline \multicolumn{5}{|c|}{ Tumor size (cm) } \\
\hline & NA & 6.57 & 8.55 & 0.03 \\
\hline \multicolumn{5}{|l|}{ N Stage } \\
\hline No & 132,51 & $58(64)$ & $32(36)$ & \\
\hline $\mathrm{N} 1$ or N2 & 171,77 & $1(11)$ & $9(89)$ & 0.003 \\
\hline \multicolumn{5}{|l|}{ Metastasis } \\
\hline No & 140,51 & $51(59)$ & $35(41)$ & \\
\hline Yes & 178,91 & $6(46)$ & $7(54)$ & 0.27 \\
\hline \multicolumn{5}{|c|}{ Fuhrman grade } \\
\hline 1 & 121,15 & $15(79)$ & $4(21)$ & \\
\hline 2 & 134,00 & $31(62)$ & $19(38)$ & \\
\hline 3 & 179,50 & $7(35)$ & $13(65)$ & \\
\hline 4 & 178,00 & $4(40)$ & $6(60)$ & 0.02 \\
\hline \multicolumn{5}{|l|}{ MVI } \\
\hline No & 136,39 & $54(65)$ & $29(35)$ & \\
\hline Yes & 179,85 & $5(31)$ & $11(69)$ & 0.01 \\
\hline \multicolumn{5}{|l|}{ Necrosis } \\
\hline No & 135,74 & $34(69)$ & $15(31)$ & \\
\hline Yes & 154,79 & $25(50)$ & $25(50)$ & 0.62 \\
\hline
\end{tabular}


Figure 1 - Photomicrographs of immunohistochemical expression of CD44s. A. Low expression of CD44s in non-neoplastic renal cortex. B. Low expression of CD44s in Fuhrman 2 CCRCC. C. High expression of CD44s in Fuhrman 4 CCRCC. Original magnification: $400 \mathrm{X}$.

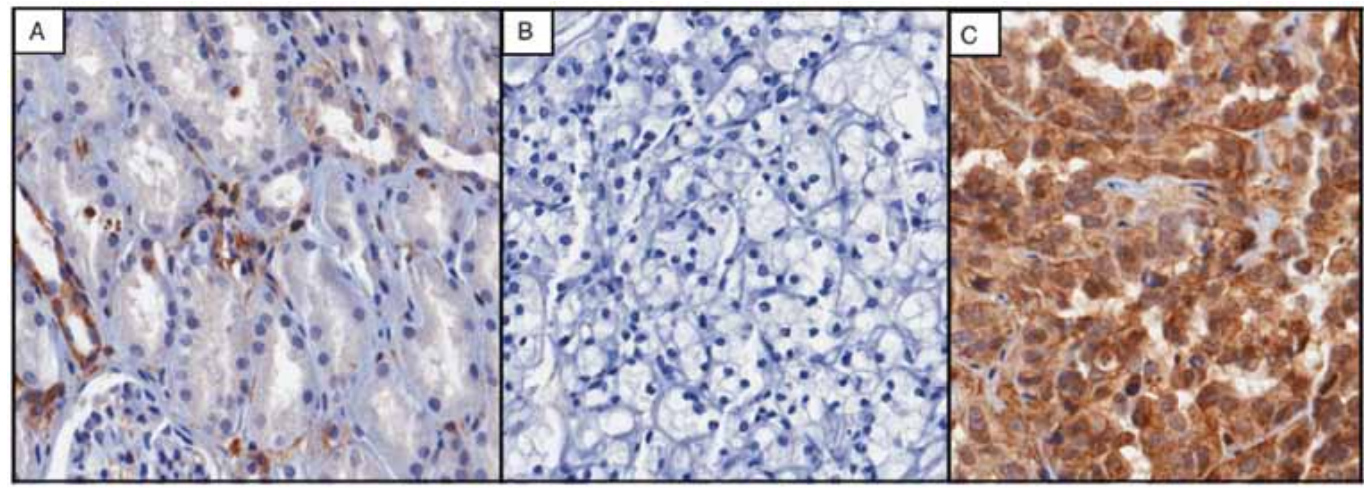

Figure 2 - Box plots for non-neoplastic tissue and CCRCC. Box represents values from lower to upper quartiles. Central line represents median.

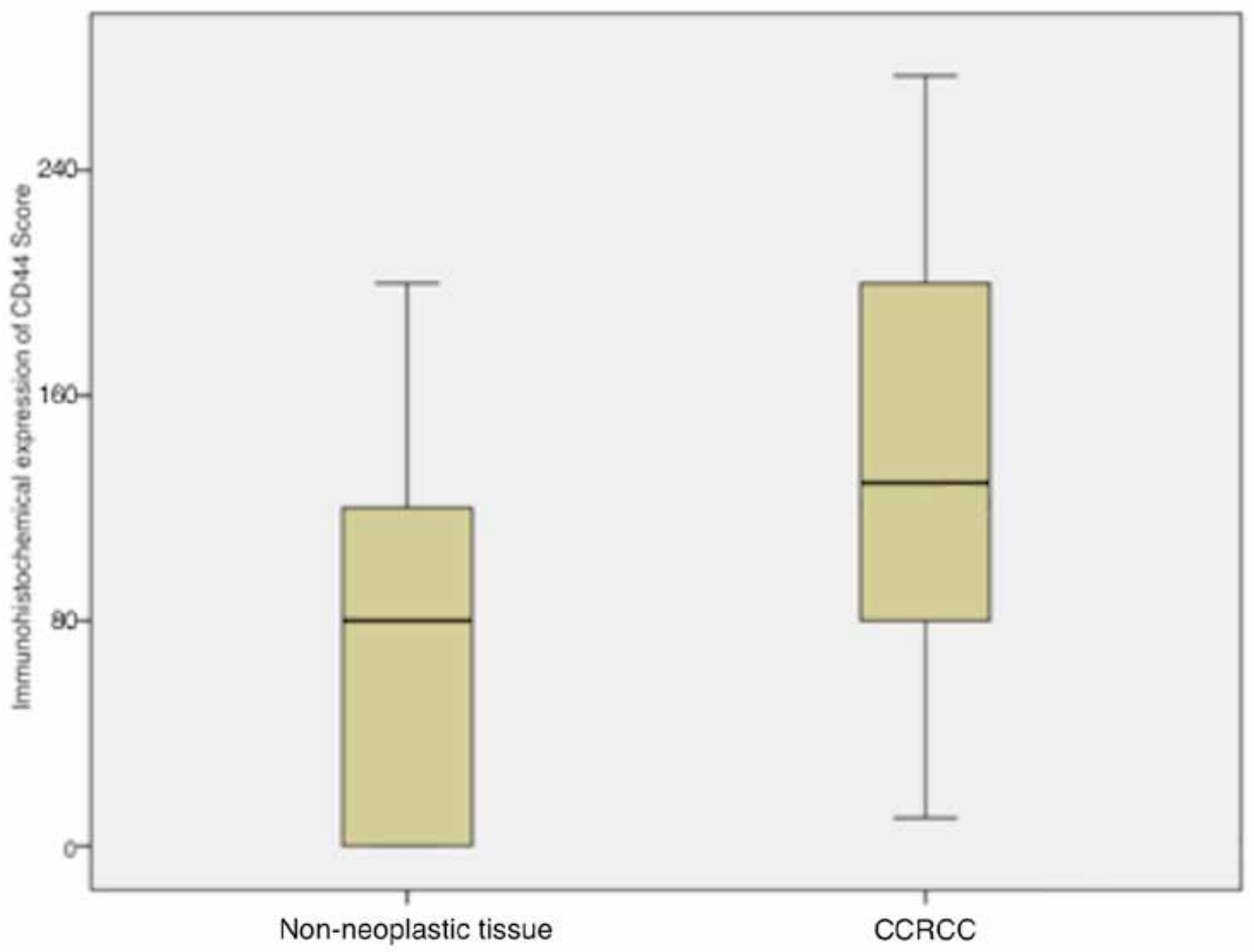


Table 2 - Cox regression analysis of DSS and PFS.

\begin{tabular}{|c|c|c|c|c|c|c|c|c|}
\hline \multirow[b]{3}{*}{ Feature } & \multicolumn{3}{|c|}{ 5-year PFS } & \multicolumn{5}{|c|}{ 5-year DSS } \\
\hline & Univariate & & Multivariate & & Univariate & & Multivariate & \\
\hline & $p$ value & $\mathrm{HR}$ & $95 \% \mathrm{Cl}$ & $p$ value & $p$ value & $\mathrm{HR}$ & $95 \% \mathrm{Cl}$ & $p$ value \\
\hline $\begin{array}{l}\text { Clinical Stage } \\
\text { (III/IV vs. I/II) }\end{array}$ & 0.001 & 13.123 & $6.126-29.854$ & $<0.001$ & $<0.001$ & 9.456 & $2.707-33.031$ & $<0.001$ \\
\hline $\begin{array}{l}\text { Tumor size } \\
(>7,0 \mathrm{~cm} \text { vs. } \\
<7,0 \mathrm{~cm})\end{array}$ & $<0.001$ & 1.453 & $0.799-3243$ & 0.230 & $<0.001$ & 2.239 & $0.831-7.789$ & 0.156 \\
\hline $\begin{array}{l}\text { Fuhrman } \\
\text { grade (III/IV } \\
\text { vs. I/II) }\end{array}$ & $<0.001$ & 1.422 & $0.764-2.344$ & 0.321 & $<0.001$ & 1.942 & $0.744-5.072$ & 0.175 \\
\hline MVI & 0.007 & 1.084 & $0.418-1.744$ & 0.612 & $<0.001$ & 1.377 & $0.516-1.947$ & 0.484 \\
\hline Necrosis & $<0.001$ & 1.432 & $0.788-1.945$ & 0.614 & $<0.001$ & 2.935 & $1.062-8.955$ & 0.05 \\
\hline Metastasis & $<0.001$ & 10.249 & $5.254-18.509$ & $<0.001$ & $<0.001$ & 7.280 & $2.988-17.112$ & $<0.001$ \\
\hline $\begin{array}{l}\text { ECOG PS } \\
(1 / 2 \text { vs. } 0)\end{array}$ & 0.01 & 0.765 & $0.601-2.477$ & 0.443 & 0.006 & 1.287 & $0.646-3.363$ & 0891 \\
\hline $\begin{array}{l}\text { CD44s } \\
\text { (High vs. Low) }\end{array}$ & 0.05 & 1.450 & $0.765-3.019$ & 0.211 & 0.009 & 1.113 & $0.389-3.182$ & 0.842 \\
\hline
\end{tabular}

$\mathbf{H R}=$ Hazard ratio; $\mathbf{C l}=$ Confidence interval.

the presence of necrosis ( $p=0.05)$ were independent predictors of DSS. However, with regard to PFS, only clinical stage $(\mathrm{p}<0.001)$ and metastasis at diagnosis $(\mathrm{p}<0.001)$ were predictive factors. CD44s tissue expression was not an independent predictor of DSS $(p=0.842)$ or PFS $(p=0.211)$ (Table-2).

\section{DISCUSSION}

Due to the increasing use of radiological procedures, particularly ultrasonography, the number of tumors that are diagnosed in the early stages is rising. Small renal masses (SRM) constitute a significant percentage of tumors that are diagnosed incidentally (14). These tumors can be benign in up to $30 \%$ of cases, and $20 \%$ to $30 \%$ of malignancies demonstrate the potential for aggressive behavior, such as tumor progression and metastasis $(14,15)$. Percutaneous renal biopsies have expanded the indications for early-stage tumors, because a significant percentage of SRM can be treated with less aggressive approaches (16). In such cases, active surveillance protocols remain a therapeutic option for patients with short 
Figure 3 - Survival analysis based on CD44s expression. (a) Disease-specific survival (DSS) for low vs. high expression of CD44s. (b) Progression-free survival (PFS) for low vs. high expression of CD44s.

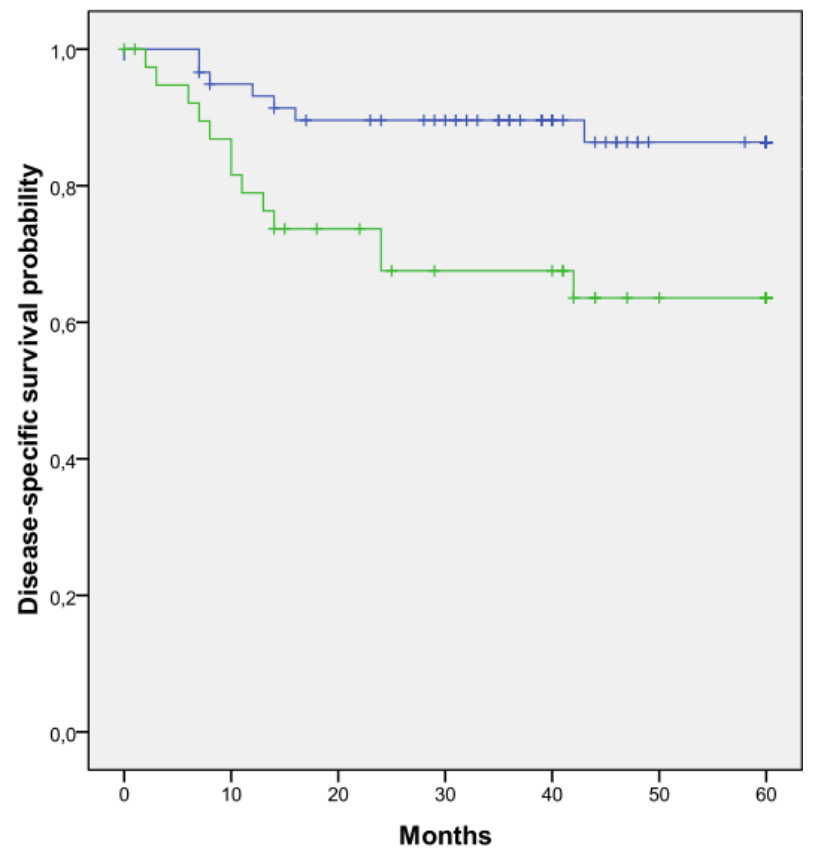

$\neg$ Low expression
- High expression
+ Low expression-
censored
+ High expression-
censored

life expectancies or presenting comorbidities limiting surgical treatment (17). Therefore, we seek to identify molecular markers that have prognostic impact and may assist in therapeutic strategies.

The cell surface glycoprotein CD44 ranges in size from 80 to $200 \mathrm{Kd}$, as described by Naor et al. in 1997 (18). A gene that lies on the short arm of chromosome 11 and mediates cell-cell interactions, cell adhesion, and migration encodes it. CD44 is the principal cellular ligand of hyaluronic acid, a glycosaminoglycan that abounds in the ECM. Described initially in mechanisms of lymphocyte activation and hematopoiesis, CD44 is an important molecule that regulates the biology of neoplastic cells, especially in interactions between cells and the ECM during tissue invasion and metastasis $(11,19,20)$.

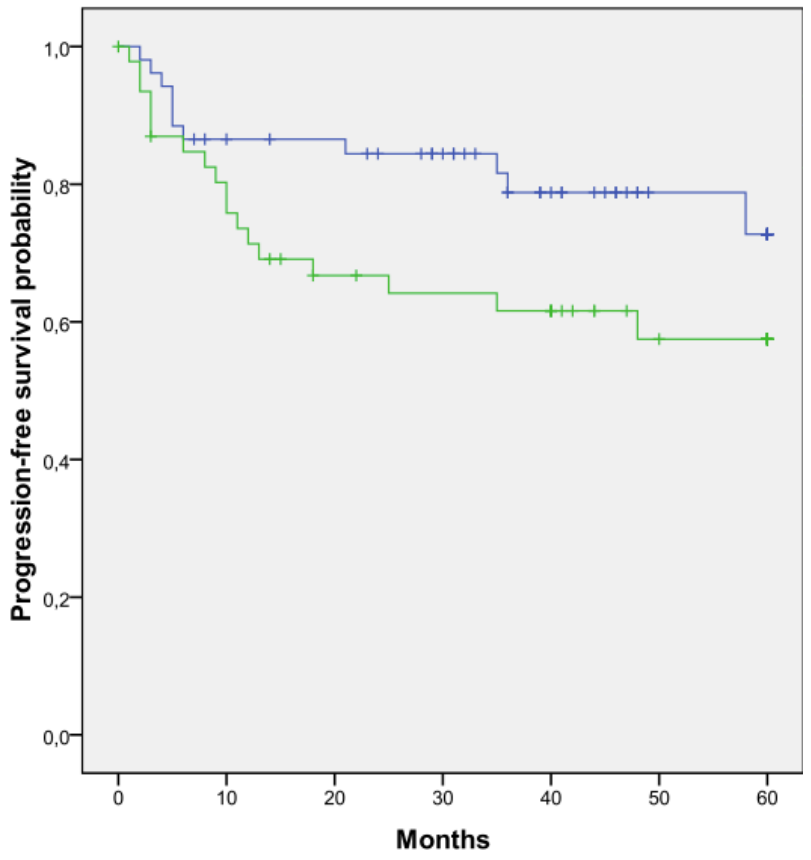

$\neg$ Low expression

$\neg$ High expression

+ Low expression-

censored

$+\begin{aligned} & \text { High expression- } \\ & \text { censored }\end{aligned}$

In our study, we observed that immunohistochemical expression of CD44s was significantly lower in non-neoplastic cells compared with RCC tissue $(p=0.01)$. Such observation only confirms previous reports regarding the metabolism of CD44. It is known that during embryogenesis, the epithelium of the Wolffian or paramesonephric duct expresses CD44, down regulating its expression during differentiation of specialized collecting tubular epithelium (21). During malignant transformation, the up regulation of CD44 in the distal and proximal tubular epithelium might reflect a more embryonic and dedifferentiated state of neoplastic renal cells. During embryogenesis, cells are highly invasive and assume many properties of metastatic cells, such as high levels of adhesion molecules and proteases (22). 
We noted that the expression of CD44s was distributed uniformly among cellular compartments. In fact, CD44 is composed of extracellular, transmembrane, and cytoplasmic domains. The extracellular domain of CD44 interacts with ECM, and the intracellular domain is associated with the actin cytoskeleton via binding to ERM (ezrin, radixin, and moesin) proteins. Cleavage of the ectodomain is mediated by membrane-associated matrix metalloproteinases such as MT1-MMP, ADAM10, and ADAM17. The release of the soluble ectodomain from the membrane is responsible for dynamic regulation of the interaction between CD44 and the ECM during cell migration on a HAcontaining substratum. The ectodomain cleavage also triggers the intramembrane cleavage of CD44. The second cleavage releases the CD44 intracellular domain into the cytoplasm, which migrates to the cell nucleus and through a feedback mechanism stimulates the production of new molecules of CD44 (23). Therefore, it is expected a uniform distribution of the staining of CD44 on the cell membrane, cytoplasm and cell nucleus as observed in our study.

The exact mechanism by which CD44 influences tumor recurrence or progression is unknown. Active migration of tumor cells in ECM is a prerequisite for tumor cell invasion and metastasis. As the principal ligand of hyaluronan, it is possible that CD44 mediates mechanisms of neoplastic cell adhesion (24) or signal transduction in tumor cells following receptor-mediated adhesion to ECM proteins (25). Still, it is known that CD44 molecule can undergo post-translational modifications such as alternative splicing. Previous studies describe CD44v5 and CD44v6 as variants presenting oncogenic potential $(10,26)$.

In our study, we observed that the expression levels of CD44s were associated with several clinical and pathological features such as tumor size $(p=0.03)$, N stage $(p=0.003)$, Fuhrman grade $(p=0.02)$ and clinical stage $(p=0.02)$. High expression levels of CD44s were associated with larger tumors, high Fuhrman grade tumors and advanced disease. It is known that high Fuhrman grade tumors have a more aggressive phenotype and are associated with higher likelihood of local invasion and distant metastasis (5). Therefore, it is expected that the metabolism of adhesion molecules such as CD44s be increased in such tumors favoring the spread of tumor cells. It is also known that larger tumors are associated with advanced disease, which explains the lower survival rates observed in patients presenting high expression levels of CD44s (14).

There are few studies describing the impact of CD44s in RCC. And many of the results are contradictory, which stimulated the research for this marker in our series. Our findings confirm those of previous published series. Paradis et al. performed a seminal study on the prognostic role of CD44s in 91 cases of RCC who were treated surgically, reporting a link between CD44s and tumor size, Fuhrman grade, and $\mathrm{T}$ stage (8). Lim et al. evaluated the prognostic value of CD44s in 125 cases of RCC of which 89 cases (71\%) were composed of patients with metastatic disease. The authors reported greater expression of CD44s in metastatic tumors and described such marker as an independent predictor of PFS in their series (9). We believe that the differences between our series in which only $29 \%$ of patients progressed to metastatic disease, and Lim et al. series might explain the fact that CD44s was not confirmed as a predictor of survival in our study. Previous series confirm our findings $(11,12)$. Altinel and his colleagues from Turkey described increased expression of CD44s in tumors presenting venous thrombi, suggesting more aggressive behavior of tumors within this group (27). However, previous series have not reported an association of CD44 with pathological variables or survival rate $(28,29)$.

Patients with higher levels of CD44s had lower DSS and PFS rates on univariate analysis. However, the pattern of expression of CD44s was not an independent predictor of survival in multivariate analysis. In fact, classical parameters such as the presence of tumor necrosis, metastatic disease and advanced clinical stage remained as significant predictors of DSS and PFS.

Our study has some limitations that must be mentioned. It represents a single-center retrospective analysis performed by a single pathologist with a small group of patients. Also, it is subject to criticism due to the immunohistochemical technique itself such as problems posed by inadequate technique of fixation in formalin material. 


\section{CONCLUSIONS}

Although immunohistochemical expression of CD44s was associated with important clinical variables such as stage and Fuhrman grade, its prognostic value was not confirmed in survival multivariate analysis. Therefore, we believe it has a limited role as a prognostic marker in patients with CCRCC.

\section{CONFLICT OF INTEREST}

None declared.

\section{REFERENCES}

1. Hernandez BY, Green MD, Cassel KD, Pobutsky AM, Vu V, Wilkens LR: 1-Preview of Hawaii Cancer Facts and Figures 2010. Hawaii Med J. 2010; 69: 223-4.

2. Sun M, Lughezzani G, Perrotte P, Karakiewicz PI: Treatment of metastatic renal cell carcinoma. Nat Rev Urol. 2010; 7: 327-38.

3. Molina AM, Motzer RJ: Clinical practice guidelines for the treatment of metastatic renal cell carcinoma: today and tomorrow. Oncologist. 2011; 16(Suppl 2): 45-50.

4. Gupta K, Miller JD, Li JZ, Russell MW, Charbonneau C: Epidemiologic and socioeconomic burden of metastatic renal cell carcinoma (mRCC): a literature review. Cancer Treat Rev. 2008; 34: 193-205.

5. Kanao K, Mizuno R, Kikuchi E, Miyajima A, Nakagawa K, Ohigashi T, et al.: Preoperative prognostic nomogram (probability table) for renal cell carcinoma based on TNM classification. $J$ Urol. 2009; 181: 480-5; discussion 485.

6. Eichelberg C, Junker K, Ljungberg B, Moch H: Diagnostic and prognostic molecular markers for renal cell carcinoma: a critical appraisal of the current state of research and clinical applicability. Eur Urol. 2009; 55: 851-63.

7. Ponta H, Sherman L, Herrlich PA: CD44: from adhesion molecules to signalling regulators. Nat Rev Mol Cell Biol. 2003; 4: 33-45.

8. Paradis V, Ferlicot S, Ghannam E, Zeimoura L, Blanchet P, Eschwége $\mathrm{P}$, et al.: CD44 is an independent prognostic factor in conventional renal cell carcinomas. J Urol. 1999; 161: 1984-7.

9. Lim SD, Young AN, Paner GP, Amin MB: Prognostic role of CD44 cell adhesion molecule expression in primary and metastatic renal cell carcinoma: a clinicopathologic study of 125 cases. Virchows Arch. 2008; 452: 49-55.

10. Lucin K, Matusan K, Dordević G, Stipić D: Prognostic significance of CD44 molecule in renal cell carcinoma. Croat Med J. 2004; 45: 703-8.
11. Tawfik OW, Kramer B, Shideler B, Danley M, Kimler BF, Holzbeierlein J: Prognostic significance of CD44, platelet-derived growth factor receptor alpha, and cyclooxygenase 2 expression in renal cell carcinoma. Arch Pathol Lab Med. 2007; 131: 261-7.

12. Yildiz E, Gokce G, Kilicarslan H, Ayan S, Goze OF, Gultekin EY: Prognostic value of the expression of Ki-67, CD44 and vascular endothelial growth factor, and microvessel invasion, in renal cell carcinoma. BJU Int. 2004; 93: 1087-93.

13. Budwit-Novotny DA, McCarty KS, Cox EB, Soper JT, Mutch DG, Creasman WT, et al.: Immunohistochemical analyses of estrogen receptor in endometrial adenocarcinoma using a monoclonal antibody. Cancer Res. 1986; 46: 5419-25.

14. Lane BR, Babineau D, Kattan MW, Novick AC, Gill IS, Zhou $\mathrm{M}$, et al.: A preoperative prognostic nomogram for solid enhancing renal tumors $7 \mathrm{~cm}$ or less amenable to partial nephrectomy. J Urol. 2007; 178: 429-34.

15. Eggener SE, Rubenstein JN, Smith ND, Nadler RB, Kontak J, Flanigan RC, et al.: Renal tumors in young adults. J Urol. 2004; 171: 106-10. Erratum in: J Urol. 2004; 171: 1639. Rubenstein JR [corrected to Rubenstein JN].

16. Remzi M, Ozsoy M, Klingler HC, Susani M, Waldert M, Seitz C, et al.: Are small renal tumors harmless? Analysis of histopathological features according to tumors $4 \mathrm{~cm}$ or less in diameter. J Urol. 2006; 176: 896-9.

17. Chawla SN, Crispen PL, Hanlon AL, Greenberg RE, Chen DY, Uzzo RG: The natural history of observed enhancing renal masses: meta-analysis and review of the world literature. J Urol. 2006; 175: 425-31.

18. Naor D, Sionov RV, Ish-Shalom D: CD44: structure, function, and association with the malignant process. Adv Cancer Res. 1997; 71: 241-319.

19. Goodison S, Urquidi V, Tarin D: CD44 cell adhesion molecules. Mol Pathol. 1999; 52: 189-96.

20. Naor D, Wallach-Dayan SB, Zahalka MA, Sionov RV: Involvement of CD44, a molecule with a thousand faces, in cancer dissemination. Semin Cancer Biol. 2008; 18: 260-7.

21. Terpe HJ, Stark H, Prehm P, Günthert U: CD44 variant isoforms are preferentially expressed in basal epithelial of nonmalignant human fetal and adult tissues. Histochemistry. 1994; 101: 79-89.

22. Ruiz P, Schwärzler C, Günthert U: CD44 isoforms during differentiation and development. Bioessays. 1995; 17: 17-24.

23. Nagano 0 , Saya $\mathrm{H}$ : Mechanism and biological significance of CD44 cleavage. Cancer Sci. 2004; 95: 930-5.

24. Underhill C: CD44: the hyaluronan receptor. J Cell Sci. 1992; 103: 293-8.

25. Koopman G, van Kooyk Y, de Graaff M, Meyer CJ, Figdor CG, Pals ST: Triggering of the CD44 antigen on T lymphocytes promotes T cell adhesion through the LFA-1 pathway. J Immunol. 1990; 145: 3589-93. 
26. Wu ST, Sun GH, Hsieh DS, Chen A, Chen HI, Chang SY, et al.: Correlation of CD44v5 expression with invasiveness and prognosis in renal cell carcinoma. J Formos Med Assoc. 2003; 102: 229-33.

27. Altinel M, Arpali E, Turhan N, Gonenc F, Yazicioglu A: Increased expression of CD44s in conventional renal cell carcinomas with renal vein or vena cava thrombosis. a retrospective evaluation of the expression of CD44s by immunohistochemical analysis in conventional RCC patients and in conventional RCC patients with renal vein or vena cava thrombosis. Urol Int. 2008; 81: 452-5.
28. Bamias A, Chorti M, Deliveliotis C, Trakas N, Skolarikos A, Protogerou B, et al.: Prognostic significance of CA 125, $\mathrm{CD} 44$, and epithelial membrane antigen in renal cell carcinoma. Urology. 2003; 62: 368-73.

29. Matusan K, Dordevic G, Mozetic V, Lucin K: Expression of osteopontin and CD44 molecule in papillary renal cell tumors. Pathol Oncol Res. 2005; 11: 108-13.

Correspondence address:

Dr. Walter Henriques da Costa Rua Cerro Corá, 1540 - Alto da Lapa São Paulo, SP, 05061-300, Brazil Telephone: + 55 11 3021-4155 